task until the end of life; and in many cases even serious decrepitude can not stop them.

So I believe that engaging in research is the best way and the only certain way for a teacher to keep himself alive intellectually and to retain his spirit and enthusiasm to the end. And even if the college he serves regards teaching and not research as its chief business, even then, I contend, he must be given a reasonable amount of time and reasonable opportunities for research in order that he may keep his intellectual health, just as he is given time for physical exercise in order that he may maintain his bodily health.

Fortunately too, the process is not an esoteric mystery open only to the elect, but a thing which can be taught and learned by ordinary men. It is true that great discoveries are not made by ordinary men -at least not often. But there is a great deal of useful work quite within the powers of almost any intelligent man which will add to the knowledge of the world and add to the happiness and usefulness of the man himself and to his success as a teacher. He must usually be taught the elements of the process and started on his career as an investigator in order to be able to accomplish much; and he must have some time and energy left over from his teaching to devote to this purpose. Both these conditions are being fulfilled more and more as time goes on; and the result will be, I believe, that the profession of the teacher will attract more able men, that they will keep their vigor and enthusiasm longer, and that the quality of their teaching will be much improved.

By the establishment and equipment of this building, Acadia is lending a helping hand toward the fulfillment of that promise, whose complete fulfillment we shall never see on this earth but toward which we are constantly making progress: "Ye shall know the truth and the truth shall make you free."

\section{H. A. Bumstead}

YALE UNIVERSITY

\section{THE CARNEGIE FOUNDATION AND ITS SERVICE PENSIONS}

THE announcement of the Carnegie Foundation that it is the intention to limit retiring allowances on the basis of a twenty-five years' service to cases of disability, has brought dismay and surprise both to those directly interested and to the larger public to whom academic interests are of concern. The report of the foundation stating this action and its reasons is now available; and the propriety as well as the wisdom of the change in rules may be discussed. ${ }^{1}$

There are three issues involved: whether the reasons given for the abandonment of one of the two fundamental provisions of the foundation are adequate, legitimate and convincing; whether independently of its desirability the abandonment of the original plan is made necessary by financial reasons; whether the sudden withdrawal from the obligations which the foundation has assumed is just.

The practical importance of the last issue entitles it to first place in the immediate situation; and on this matter it is possible

${ }^{1}$ Since the situation requires a certain freedom of expression, I may be permitted to explain that I have publicly and privately expressed the most cordial approval of the foundation, its purposes and its provisions, particularly and above all of the provision which is now to be withdrawn. Articles in the Dial will sufficiently indicate this fact. An article in the North American Review will further indicate the high opinion I formed of the influence of the foundation and of the necessity of including the state universities in order that this influence shall be of national scope. This commendation must stand as evidence of my interest and favorable attitude towards the foundation and its mission. 
to let others speak. Professor Lovejoy ${ }^{2}$ draws attention to the ethical obligations involved toward those men who very naturally were looking forward in the immediate future to a retirement under the provision so unexpectedly withdrawn. It must be evident that the expectations thus aroused carry with them every essential factor of an implied contract. The withdrawal of this right affects at once a group of men who were looking forward to taking advantage of its arrangements within the next five or ten years, and affects them in a manner so particularly unfortunate that they need not hesitate to refer to this personal aspect of the situation. But the yet more serious side of this sudden withdrawal is that it reflects so unfavorably upon the foundation itself. One of the prominent arguments used by the foundation in establishing its provisions was that the professor could look far ahead and with absolute security to the benefit thus to be conferred. An institution that radically changes the essential scope of its purpose within four years is not suggestive of security. It will be extremely difficult, even if the present problem is reconsidered and more satisfactorily solved, to assure professors that other provisions will not be withdrawn and with no more convincing reasons. Nor can any refuge be taken in the fact that the foundation reserved to itself the power to change its rules. Every reasonable understanding of that proviso would interpret it to refer to minor changes in administration, not to a radical and far-reaching abandonment of a distinct and explicit provision. On this point the Evening Post, of February 28, leaves nothing to be said, unless it be to indicate that Professor Lovejoy does not stand alone in his fear that "a body which at a moment's notice abandons one of the two purposes constituting its proclaimed raison d'être is equally likely to modify ${ }^{2}$ Nation, February 3. the other to any assignable degree." The editorial concludes thus:

Dr. Pritchett says that "the expectation that this rule would be taken advantage of almost wholly on the ground of disabilities has proved to be ill-founded"; but if this is meant as a defence against the charge of want of good faith, it betrays a misty notion of the nature of moral obligations. If disability was meant to be the basis from the beginning, nothing would have been easier than to say so; if it was not, then it was absolutely honorable, right and proper for any man to avail himself of the retiring allowance offered him without reference to any question of disability. If an error was made in the first place, rectify it by all means; but first stand by the consequences of your error, to the extent demanded by the ordinary standards of honorable conduct between man and man. An absolutely essential requirement of a properly constituted university pension system is that it shall not place upon the professor any sense of obligation other than what is inevitable and inherent in such a system; he must feel that he has earned his pension, just as he has earned his salary, by his past services. If to retire under a pension is to mean to retire under a censorship, the Carnegie Foundation may conduce to the material comfort, but will certainly not conduce to the dignity or the self-respect of the profession of university teaching. And, to come back to the main point, the homely obligation of fulfilling in a reasonable measure substantial expectations that have been raised by one's own declared intentions is a duty antecedent even to the high purposes to which the Carnegie Foundation is dedicated.

The immediate object of endeavor may well be to bring to the attention of the trustees, in as convincing a manner as possible, the categorical imperative of the obligation which they have assumed. There is much to be said for the view that this obligation extends to all institutions that have already become accredited to the foundation. But moral obligations are not incompatible with a reasonable regard for the practical situation. If the foundation could be prevailed upon to adopt in place of the measure now upon its records, an 
announcement that unless the financial and other conditions are decidedly altered, the foundation will find it advisable to withdraw (except in cases of disability and such other cases as may be specified) the right of an allowance on the service basis, after the year 1915 or 1920 , it may be confidently expected that the academic world will accept this announcement with deep regret, but without that feeling of righteous indignation or moral resentment which is so forcibly expressed by the writer of the editorial just cited. The first and paramount obligation is for the foundation to clear its record and restore confidence in the value of its mission, in the directness of its methods, and the unquestioned acceptance of its obligations. A ten-year period is none too long for such an announcement; for it may well be that with the situation clearly foreseen, measures may be taken to continue the service retirement upon some modified basis which will tend to the advancement of the profession, and to the retention of the influence of the foundation.

To proceed to the consideration of the situation as it stands: The report shows that as yet only one fourth of the funds for retirement allowances is expended for service grants, while three fourths of the funds go for age grants. It appears that this is regarded as a large ratio; but that depends upon how one views the desirability and the value of service allowances. One who believes strongly in the value of such allowances will hold that to them might properly (in an experience of twenty to thirty years) be assigned the larger rather than the smaller share of the funds. But the argument advanced by the report expresses dissatisfaction with the working of this retirement provision for the following reasons, and concludes that the service pension for professors is a mistake: First, that universities are likely to bring undue pressure to bear to retire professors who are willing and should be permitted to continue their service. Second, that there will arise a "tendency of the teacher assured of a retiring allowance to become ultra-critical toward the administration." Third, that the hope that such allowances would prove an aid to research is one which on the whole seems illusive. Fourth, that too many men accept the allowance because they are tired of teaching, or wish to go into business, or to engage in some activity irrelevant to the purpose of the foundation. "It seems that this rule offers too large a temptation to certain qualities of universal human nature" - but yet, if universal, why were they not considered three or four years ago? Fifth, that of forty men retired on this basis, only twelve retired for disability. This is regarded as a disproportion, although there is nothing in the original provision which suggests that the main purpose of the rule was to provide for cases of disability. Sixth, while there is no explicit statement that this is a cause for the action, the conclusion may be inferred that a continuance of this policy would overtax the available funds.

To the first it might be replied that if the universities so offend, the foundation should withdraw the right of retirement by the universities until they can show good cause for their actions; to the second, that the sin of being critical towards the administration is a form of lêse majesté not likely to be seriously regarded in a professedly democratic community, at all events not so seriously as to cancel a right (?) to a pension; to the third, that it all depends upon what manner of men occupy professorial chairs, and that the purpose of the foundation is to so improve conditions that the right type of men may more readily be induced to enter this career; to the fourth, that the needlessly severe conditions of the 
academic life are more responsible for this situation than the "human nature" of the professors; to the fifth, that it is rather complimentary to the physique of the teaching profession that more have not qualified. for the privilege of disabilityor are those who succumbed the unhonored martyrs who are not even a burden to the Carnegie Foundation?; to the sixth, that foresight in not promising what can not be fulfilled is demanded of every business-like institution.

But it is obvious that in reality too many questions are involved in this issue to make it possible, or in the present connection desirable, to consider them in detail. It is sufficient to call attention to the fact that every system, however worthy or wise, is open to abuse; but the abuse must be very considerable and extended before it justifies so drastic a cure. It must be remembered that in every transition from one system to another, there necessarily follows a period of adjustment, and that the value of the provision can be decided not by its abuses but by its uses, and that only after the academic career in this country has become adjusted to the Carnegie provisions. It would seem to be much fairer to wait twenty years and see what men actually do who withdraw under this provision, before deciding that it is a mistake. In brief, the question as to how far this provision of the foundation is a mistake can not at this stage be decided by the experience obtained, but must be appraised according to the value attached to this method of advancing the attractiveness of the academic career. This is so wholly a matter of opinion that there is little to be gained by opposing one opinion to another; but it should be pointed out that at least one member of the board of trustees of the foundation, President Jordan, has taken a very opposite view, and tells the public that "the retirement of men in good health to pursue their studies unhampered may be regarded as one of the most important functions of the Carnegie Foundation." If what is regarded on the one hand as a mistake is regarded on the other as a most important function, this conflict of view is sufficient to make one pause before justifying so radical a step by so questionable a consideration.

But at this point it becomes quite impossible to avoid the reflection that the actual considerations are really the financial ones, and that the reasons given would of themselves (without the financial difficulty) have seemed quite inadequate to many who participated in the decision. This reflection is again a very serious one. If the provision had to be abandoned for financial considerations, that fact should have been stated prominently, frankly and without complication with other reasons. ${ }^{3}$ All universities are so troubled by a lack of funds that such a statement would at once seem natural and in an academic community would command full sympathy. And so again if this provision is not a mistake, but merely another instance in which a high and far-reaching ideal has to be given up for a more limited range of service, that is likewise a very familiar academic situation with which every one

${ }^{3}$ In regard to the financial side, it may be recalled that in Mr. Carnegie's original letter giving ten million dollars for the foundation, it was said that "expert calculation shows that the revenue will be ample for the purpose." If this calculation, however expert, has proved to be a mistake, it is that mistake which most needs acknowledgment. At the same time it should be understood that the load of the service allowance is not wholly an additional burden upon the foundation, since with the ordinary expectation of life some of those who retire on the less favorable basis but near to the age of sixty-five will draw no more from the foundation than if they retired upon the more favorable basis a few years later. 
sympathizes. If the provision is a mistake, no one can be expected to make an effort to prevent its withdrawal or to secure larger financial support to make possible its continuance; but if the provision is a most desirable and important function of the foundation, it should be possible to enlist the interest that has already so generously provided these funds to further support the foundation and render it as comprehensively efficient as was originally intended. Here as everywhere in academic administration, it is most essential that the right reasons be stated for the action taken, so that academic interests and financial questions may not be confused.

President Jordan distinctly states that it is the financial difficulty that is largely responsible for the withdrawal of the provision. If this is the case, the responsibility of anticipating this condition four years ago can hardly be avoided; and it becomes difficult to explain how so recently as two years ago an actual extension of the liberality of the retiring provisions was made. Originally the maximum grant was limited to $\$ 3,000$, but in 1907 this was advanced to $\$ 4,000$. Now it appears that this change affects on the age basis only those whose salaries range from $\$ 5,300$ to $\$ 7,200$, and on the twenty-five-year basis only those whose salaries range from $\$ 6,800$ to $\$ 9,200$. It is certainly an unpleasant reflection that almost all those who might be affected by this increased allowance are university presidents, many of them perhaps members of the board that made this decision. Surely if funds were likely to be inadequate, this was hardly the point at which an increased generosity was permissible.

It should be added that there is another factor in the situation, which appears in the instructions to the executive committee, which is directed to safeguard the interests of the following classes of cases: (a) those who have research work in view and have shown themselves unmistakably fit to pursue it; (b) those whose twenty-five years of service include service as a college president; and, (c) those in whose mind a definite expectation has been created by official action that they will be accorded the benefits of the foundation within the year 1910 .

These instructions appear in President Jordan's letter; and it is at least a slight consolation to be informed through his letter that there is no intention to enforce the rule retroactively for the present year. The change in the rules consequent upon these instructions indicates that in spite of the withdrawal of the service allowance the trustees are willing to grant an allowance " to the rare professor whose proved ability to research promises a fruitful contribution to the advancement of knowledge, if he were able to devote his entire time to study or research; and the trustees may also grant [a similar allowance] to the executive head of an institution who has displayed distinguished ability as a teacher and educational administrator." This censorship by the foundation of the merits of applicants clearly destroys the initial policy of the foundation which gave to the professor the right of a pension. The pension as a favor, with an emphasis upon that aspect of the academic career least germane to the purposes of the foundation, is a totally different matter from the far-reaching and beneficent policy which brought to the foundation its most cordial supporters. It is peculiarly difficult to understand why a policy which for the professor has proved to be a mistake shall yet be reserved as a privilege for the president; while again, it seems peculiarly invidious to insert the adjective "rare" before the "professor" and omit it in case of the "president."

While I can not agree that the service allowance can within so short an experience 
be proved to be a mistake, I believe that there is one factor in the constitution of the foundation that this brief experience proves to be a mistake. I refer to the absence from its board of trustees of a number of men who can and will safeguard, as well as express and understand, the interests of the professors. Presidents can, if they will, do this in part; but they can not fully represent the academic and the administrative interests (both fully justified) at once. Is it not a fair presumption that if half of the members of the board had been university professors, the precipitate withdrawal of the service provision-not to say the indefensible repudiation of obligations presently to mature - would have been avoided?

And so I ask whether it would not be well for the foundation to collect opinions upon the desirability of service allowances and have them brought before the trustees. If it shall prove that a considerable number agree with President Jordan, it is to be hoped that measures will be taken to secure for the foundation the exercise of this important service. I may repeat in this connection a proposal that was suggested years ago, that the universities themselves be required to provide part of the funds for retiring allowances; that at the outset they should have been asked to consent to a contingent provision that if at any time the service allowance proves to be too heavy a tax upon the foundation, the universities shall carry the load until the men reach the age of sixty-five; or equally it might have been urged that it is a greater privilege for the foundation to provide the allowance after twenty-five years' service and let the universities carry the age provision. I may also be permitted to say that from the outset it seemed to me that quite the wisest provision to really advance the academic profession was to have made possible a system of half retirement, upon which men after twenty-five years of service shall be relieved of most of their teaching, while yet they give to the university the influence of their presence, their reputation and their ripe scholarship.

Not alone has the foundation without notice withdrawn a portion of its program of most vital concern to the academic profession, but the official channel of its expression announces that the change thus decided upon "will command the approval of the great body of devoted and able teachers and is in accordance with the spirit of the rules as originally framed." For my part, I have no choice but to incur the odium of exclusion from this approval and content myself with showing what modest devotion or ability I may possess in other directions, in order to retain my right of protest that the change itself (whether enforced or not) is most regrettable, and that there is nothing in the spirit of the original rules that foreshadows the interpretation that has now been made. It is pertinent to recall that a point of great emphasis in the original provisions is that the right to a retiring allowance shall come to the professor undisputed and as a result of his own initiative. It was this feature that brought the largest commendation to the foundation and that was instrumental in inducing institutions that already had a pension system to give it up in favor of the Carnegie provisions. There were many who four years ago predicted that in spite of this provision the fund would be administered as a semi-charitable old-age pension fund. To this objection it was then possible to reply that the twenty-five years retirement allowance distinctly gave to the professor some control of the use of the allowance in a dignified manner and to serve the cause of education. If this provision is abandoned, it is not quite obvious how one 
is to reply to the view that incapacity and old age are suggestive of charity and not of the advancement of the teaching profession. As one who is interested in the causes which the foundation was instituted to promote, I can not look with equanimity upon the curtailment of the influence of the foundation as now proposed, and I am willing to risk the confusion of personal interest with a disinterested view of the benefit to the teaching profession in order that the question may be seen as a whole and not decided abruptly by mere temporary expediency.

Two obligations seem to rest upon the foundation in order to reinstate its influence and to justify its mission. In an unequivocal and equally in a generous manner it must meet the obligations which its announcements have aroused in the minds of those who within a few years will be in a position to take advantage of its formulated provisions; and in the second place, to reinstate confidence in its methods, there should be a plain statement to the effect that the financial difficulty is or is not the determining cause of the present action. If such prove to be the case, let the arguments against a system be held in reserve, and let the actual situation be met in that same helpful spirit which has characterized so many of its important and beneficial decisions.

\section{Columbia University,}

JOSEPH JASTROW

March 2, 1910

\section{AN AMERICAN RESEARCH INSTITUTION IN PALESTINE. THE JEWISH AGRICUL- TURAL EXPERIMENT STATION AT HAIFA}

A NEW American institute of research has just been incorporated in New York under the title of the "Jewish Agricultural Experiment Station," with a board of trustees composed of Mr. Jul. Rosenwald (Chicago), president, Mr. Paul M. Warburg (New York), treasurer, Miss Henrietta Szold (New York), secretary and Dr. Cyrus Adler (Philadelphia), Mr. Sam S. Fels (Philadelphia), Judge Jul. W. Mack (Chicago), Dr. J. L. Magnes, Mr. Louis Marshall, Dr. Morris Loeb, Mr. J. B. Greenhut (New York) and Dr. O. Warburg (Berlin, Germany), members of the board.

This new experiment station is to be located at the foot of Mt. Carmel in Palestine, seven miles from Haifa, and is the first agricultural institution of research supported by private American capital to be established in a foreign country. The funds for the station have been furnished by several philanthropic Jews. Messrs. Jacob H. Schiff, of New York and Jul. Rosenwald, of Chicago, have furnished the first $\$ 20,000$ necessary for the initial equipment. The minimum budget of $\$ 10,000$ a year has been assured by Messrs. Schiff and Rosenwald, together with Mr. Paul M. Warburg (of Kühn, Loeb \& Co.), Mr. Is. N. Seligman, Mr. Isidor Straus and others.

As an American institution in the Levant and carrying the American experiment station idea abroad, this newly incorporated instituton can not fail to interest American experiment station workers, since its purposes are the scientific study and development of the agricultural resources of one of the oldest parts of the old world, as rich in latent wealth as it is in historical and religious interest.

The director of this new station, Mr. Aaron Aaronsohn, is already known to quite a circle of experiment station workers, having spent a number of months in making comparative studies of the agricultural, climatic and botanical conditions of our southwestern country, for the purpose of comparing them with present conditions in Palestine, in which studies he has been deeply impressed with the remarkably close agricultural resemblance existing between California and Palestine. Mr. Aaronsohn is peculiarly well equipped to establish such an institution in Palestine, having spent fourteen years of his life in agricultural and botanical explorations throughout that region and having made himself familiar with Turkish, Arabic and 